DOI 10.37882/2223-2974.2020.11.18

\title{
РОЛЬ ИННОВАЦИОННЫХ ПОДХОДОВ К ВЫБОРУ ПРЕДПРИНИМАТЕЛЬСКИХ СТРУКТУР КАК ОБЪЕКТОВ ИНВЕСТИРОВАНИЯ
}

\section{THE ROLE OF INNOVATIVE APPROACHES TO THE SELECTION OF ENTREPRENEURIAL STRUCTURES AS OBJECTS OF INVESTMENT}

\section{E. Ksenofontova \\ O. Gulyaeva}

Summary: In order to select investment objects, heads of organizations use various methods and techniques. The most important selection criterion is the profitability of the organization. The article discusses ways to improve the activities of entrepreneurial structures for the necessary changes in the approaches to the formation of a functional business model of entrepreneurial actions.

Increasing the level of efficiency of the organization is impossible without detailed planning of the production and sales activities of the organization and the involvement of the maximum number of employees in the process of improving activities to improve the customer-oriented processes of business structures.

The article pays special attention to a set of measures for the development of regulations aimed at improving product quality, improving product properties, reducing costs, and reducing labor costs. The authors note that the effectiveness of the investment policy in the activities of entrepreneurial structures is impossible without high-quality regulation of business processes at all levels, without clear, clear standards that ensure maximum transparency and efficiency. Modern organizations should pay attention to monitoring statistics on indicators of the quality of personnel labor, customer-oriented processes, the profitability of the implementation of resources, promptly and flexibly carry out a set of measures to improve approaches to modernizing business processes, and develop the necessary programs for long-term digital strategic planning.

Keywords: investments, customer-oriented processes, profitability, entrepreneurial structures, business processes.

\author{
Ксенофонтова Екатерина Андреевна \\ соискатель, Санкт-Петербургский государственный \\ экономический университет \\ tyuksenofontova@mail.ru \\ Гуляева Ольга Анатольевна \\ к.т.н., дочент, Петербургский государственный \\ университет путей сообщения
}

Аннотация: С целью выбора объектов инвестирования руководители организаций применяют различные методы и приемы. Важнейшим критерием выбора является рентабельность организации. В статье рассматриваются пути совершенствования деятельности предпринимательских структур для проведения необходимых изменений в подходах к формированию функциональной бизнес-модели предпринимательских действий.

Повышение уровня эффективности деятельности организации невозможно без детального планирования производственной и сбытовой деятельности организации и вовлечения максимального числа сотрудников в процесс улучшения деятельности по повышению клиентоориентированности процессов предпринимательских структур.

В статье уделено особое внимание комплексу мероприятий по разработке регламентов, направленных на повышение качества продукта, улучшение свойств продукта, снижение себестоимости, снижение расходов на оплату труда. Авторы отмечают, что результативность политики инвестирования в деятельность предпринимательских структур невозможна без качественной регламентации бизнес-процессов всех уровней, без понятных, четких стандартов, обеспечивающих максимальную прозрачность и эффективность. Современные организации должны уделять внимание мониторингу статистики по показателям качества труда персонала, клиентоориентированности процессов, рентабельности реализации ресурсов, оперативно и гибко проводить комплекс мероприятий по совершенствованию подходов модернизации бизнес-процессов, разработке необходимых программ долгосрочного цифрового стратегического планирования.

Ключевые слова: инвестиции, клиентоориентированность процессов, рентабельность, предпринимательские структуры, бизнес-процессы.

и переменных затрат данного товара. Наиболее наглядно расчет точки безубыточности может быть представлен на рисунке 2.

При анализе расчетов и графиков, можно заметить следующую закономерность: при уменьшении цены на товар или услугу, точка безубыточности увеличивается, и, соответственно, при росте цены на продукт данный показатель сокращается.

Точка безубыточности, безусловно, один из важней- 


\section{Прогноз инвестиций}

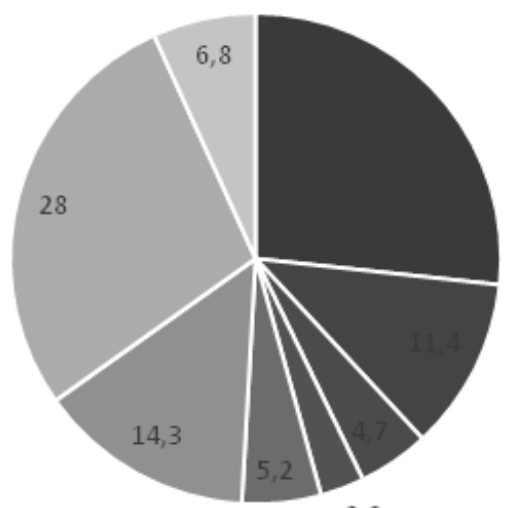

2,9

- недвижимость и строительный комплекс обрабатывающая промышленность

- торговля

- образование и здравоохранение

- агропромышленный комплекс

- транспорт и связь

- топливно-энергетический комплекс

прочие

Рис. 1. Прогноз инвестиций по отраслям экономики на 2020г.

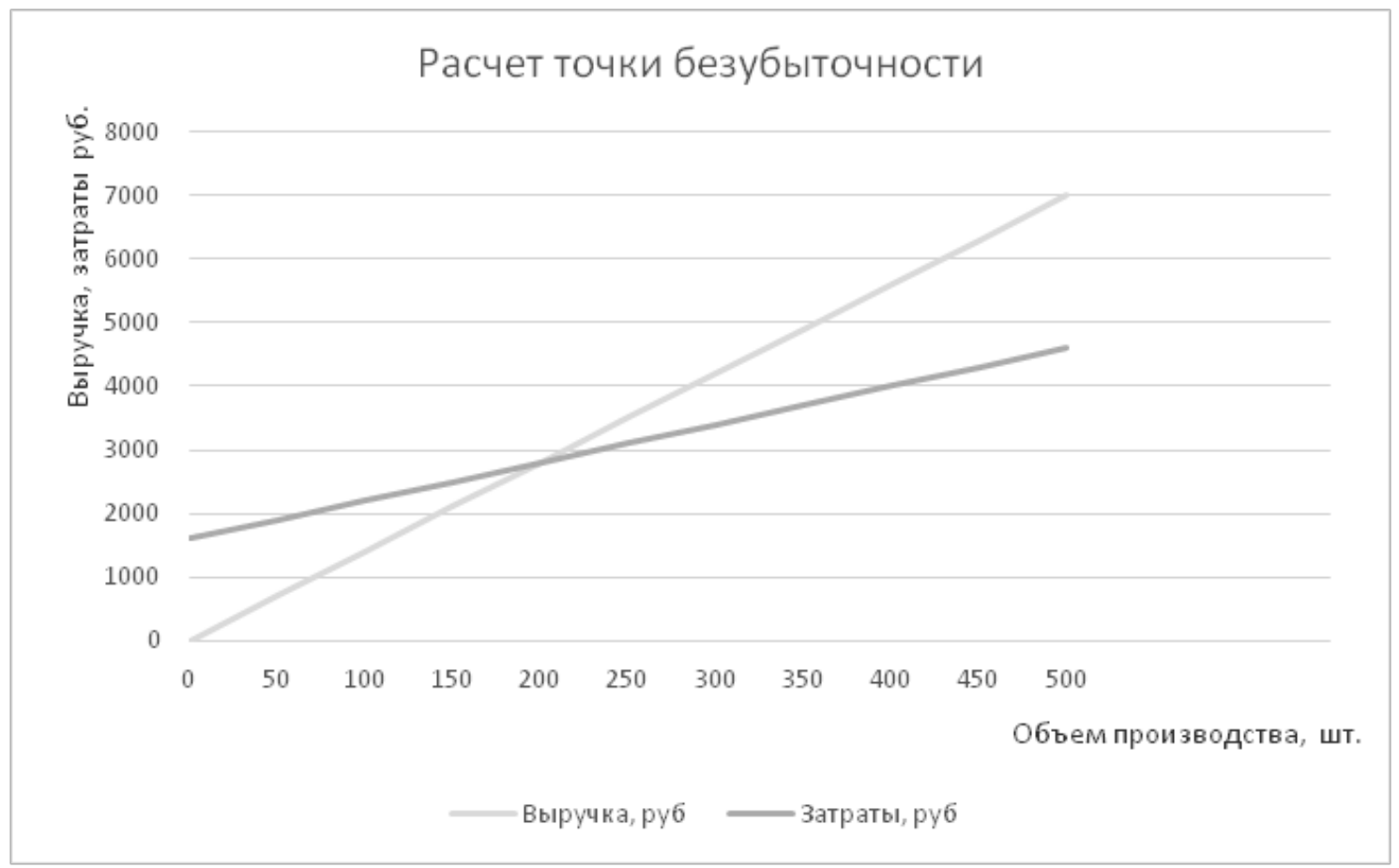

Рис. 2. Расчет точки безубыточности

ших показателей, которые позволяет обосновать экономические аспекты ведения бизнеса [1]. При расчете этого показателя руководитель узнает о конкретных значениях цены и издержек, которые необходимы для детального планирования производственной и сбытовой деятельности организации.
С целью структурировать совершенствование бизнес-процессов необходимо проанализировать все виды документации подразделений [2].

Формирование функциональной бизнес-модели предпринимательских действий можно разделить на 
следующие категории: - Главные - от них зависит доход компании. Они предполагают значимость для покупателя. Сюда относятся подобные области, равно как реализация, обслуживание, изготовление.

- Опорные - необходимы с целью предоставления стандартной деятельности фирмы. Данные информативные технологические процессы, адвокатское, промышленное поддержание, а также пр.

- Движение управления - влияют на свойство исполнения ключевых действий (экономическое составление плана, пр.).

Преодолев эту проблему, появляется возможность распределения абсолютно всех проходящих в фирме уровней:

1. Избирается один из области деятельности компании, предположим, руководство капиталами.

2. В рамках одной области акцентируется движение. Таким образом, подобранная нами в первоначальной степени область заключается в бюджетировании, компании экономного комитета, размещение резервных капиталов.
3. Движение соответствует с вариантом цикла из 4 стадий: планирование, выполнение, контролирование, подведение итогов/управленческого влияния.

После формирования модели следует определить ответственных за функционирование процессов.

После того, как матрица ответственности сформирована, можно определить перечень функций, присущих каждому подразделению организации. В случае, если роль каждого руководителя четко определена конкретными функциями конкретных подразделений, а все бизнес-процессы разложены по полочкам, обязанности каждого члена коллектива становятся максимально понятными и прозрачными [3].

Основываясь на уже описанных бизнес-процессах, следует разработать документ, описывающий порядок мониторинга статистики уровня качества труда персонала, функционирования бизнес-процессов, оценки эффективности [4]. При внесении каких-либо изменений в бизнес-процессы разрешается редактирование

\section{Документ уровня владельца процесса}

Назначение:

Как управлять процессом?

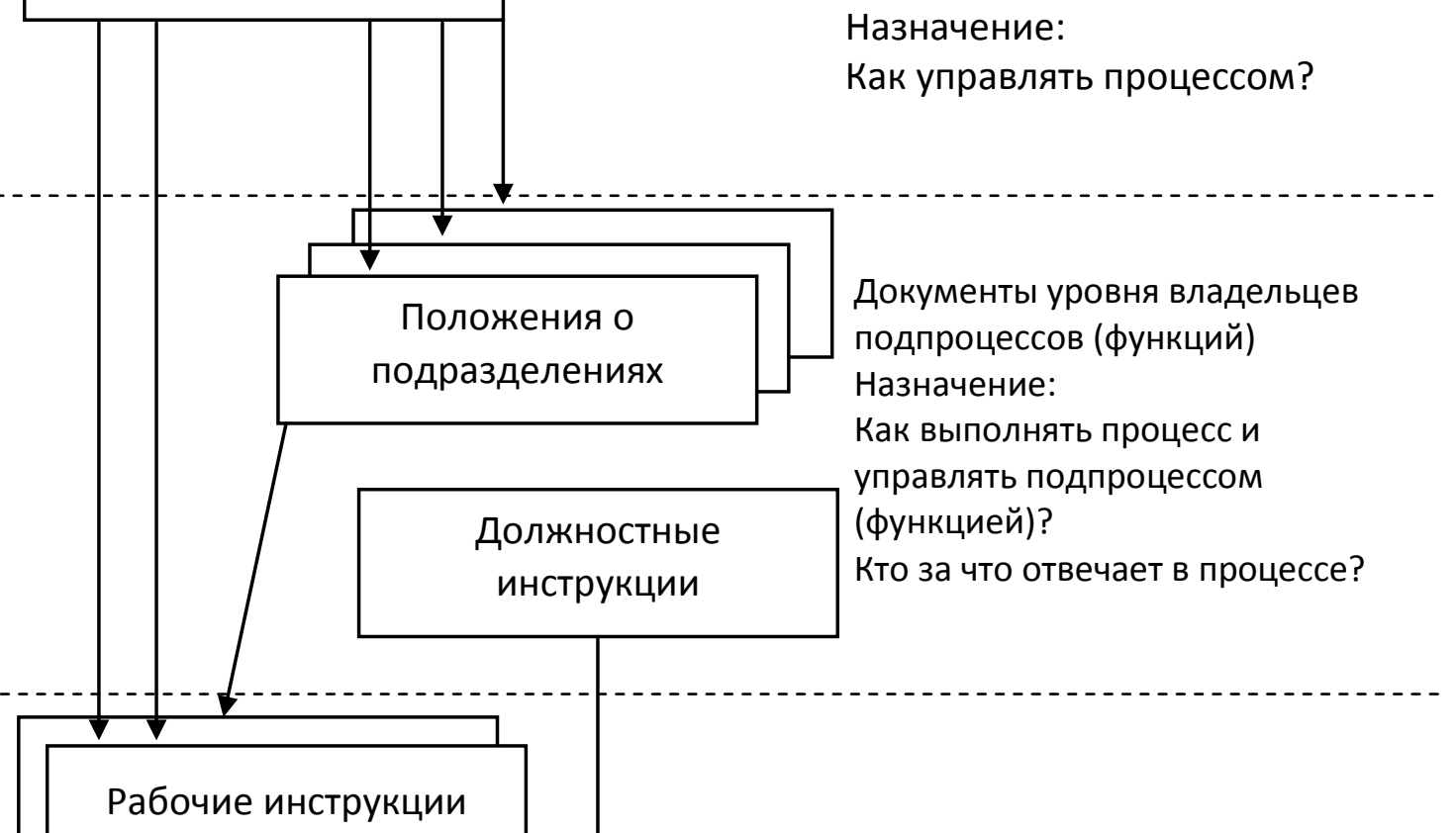

Документы уровня исполнителей функций и операций

Назначение:

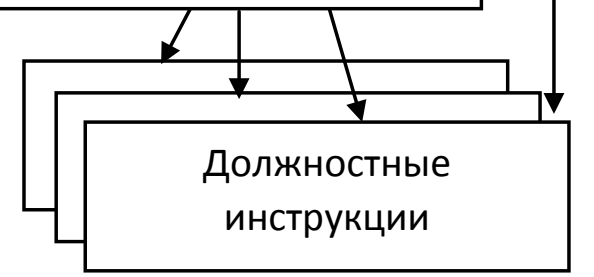

Как выполнять функции и операции?

Рис. 3. Функциональная бизнес-модель формирования регламентов 
показателей. Для регламентации бизнес-процессов необходимы понятные, четкие стандарты, прописанные для бизнес-процессов всех уровней, обеспечивающие максимальную прозрачность и эффективность [5]. На рисунке 3 представлена специальная функциональная бизнес-модель, рекомендованная для формирования регламентов.

Для разработки документа необходимо представление процесса в виде рисунка и, соответственно подготовка самого документа, путем объединения всей информации. Большую часть времени занимает вовсе не подготовка регламента, как может показаться на первый взгляд, а его дальнейшая реализация. Должны пройти этапы согласования, утверждения, внесения в специальный корпоративный реестр, размещение информации в интернете, для доступа к ней сотрудников, и их обучения. Информация спускается сверху вниз: обучение сначала проходят руководящие работники, и лишь потом они организуют процесс обучения подчиненных.

То, насколько правильно, организована деятельность организации, определяет эффективность его работы, поэтому все бизнес-процессы необходимо отлаживать с особой точностью. Такой подход позволяет существенно снизить риски, повысить финансовые и репутационные показатели.

При выборе объектов инвестирования предпринимательские структуры должны руководствоваться:

- инновационными подходами модернизации бизнес-процессов;

- полноценностью программ долгосрочного цифрового стратегического планирования;

- нацеленностью организации на постоянный рост прибыли;

- клиентоориентированностью процессов организации;

- вовлеченностью сотрудников [6,7].

\section{ЛИТЕРАТУРА}

1. Гуляева 0.А., Мардас А.Н., Мардас Д.А. Прогнозная оценка результативности стратегии развития производственно-экономической системы/ СПбГэту, Дискурс. 2016. № 2.

2. Ксенофонтова Т.Ю. Методологические аспекты использования нематериальных активов в процессе управления конкурентоспособностью производственных предприятий Ксенофонтова Т.Ю., / монография / Федеральное государственное бюджетное образовательное учреждение высшего профессионального образования «Санкт-Петербургский государственный инженерно-экономический университет», Санкт-Петербург, 2012.

3. Ксенофонтова Т.Ю. Региональные особенности управления развитием человеческого и интеллектуального капитала в условиях изменений внешней среды /Ксенофонтова Т.Ю., Автореферат диссертации на соискание ученой степени доктора экономических наук / Санкт-Петербургский государственный экономический университет, Санкт-Петербург, 2014

4. Мардас А.Н., Гуляева 0.А., Мардас Д.А. Модели построения делового портфеля в рамках корпоративной стратегии / Известия Петербургского университета путей сообщения, 2007, № 1 (10)

5. Мардас А.Н., Кадиев И.Г., Гуляева 0.А. Методы стратегического анализа в управлении инвестиционно-инновационной деятельностью в региональных хозяйственных комплексах / монография / Санкт-Петербург, СПбГЭТУ ЛЭТИ, 2011.

6. Мардас А.Н., Кадиев И.Г., Гуляева 0.А. 0 возможностях и методах прогнозирования инновационных процессов Известия СПбГЭТУ ЛЭТИ, 2010 . № 9.

7. Облачные технологии: панацея или маркетинг? Ксенофонтова Т.Ю., Мардас А.Н., Гуляева 0.А., Чернобай Н.С., В сборнике: Умные технологии в современном мире. Материалы юбилейной всероссийской научно-практической конференции, посвященной 75-летию Южно-Уральского государственного университета. Под редакцией И.А. Баева. 2018. 